\title{
Expression of nitric oxide synthases and effects of L-arginine and L-NMMA on nitric oxide production and fluid transport in collagenous colitis
}

A Perner, L Andresen, M Normark, B Fischer-Hansen, S Sørensen, J Eugen-Olsen, J Rask-Madsen

\begin{abstract}
Background and aims-Luminal nitric oxide (NO) is greatly increased in the colon of patients with collagenous and ulcerative colitis. To define the source and consequence of enhanced NO production we have studied expression of NO synthase (NOS) isoforms and nitrotyrosine in mucosal biopsies from these patients. In addition, effects on colonic fluid transfer caused by manipulating the substrate of NOS were studied in patients with collagenous colitis.
\end{abstract}

Patients-Eight patients with collagenous colitis, nine with active ulcerative colitis, and 10 with uninflamed bowel were included.

Department of Gastroenterology, Herlev Hospital, DK-2730 Herlev, University of Copenhagen, Denmark

A Perner

L Andresen

J Rask-Madsen

Department of Pathology, Hvidovre

Hospital, DK-2650

Hvidovre, University

of Copenhagen,

Denmark

$M$ Normark

B Fischer-Hansen

Department of Clinical Biochemistry,

Hvidovre Hospital,

DK-2650 Hvidovre,

University of

Copenhagen, Denmark

S Sørensen

Clinical Research

Unit, Hvidovre

Hospital, DK-2650

Hvidovre, University

of Copenhagen,

Denmark

J Eugen-Olsen

Correspondence to:

Professor J Rask-Madsen, Department of

Gastroenterology C-112,

Herlev Hospital, Herlev

Ringvej 75, DK-2730 Herlev,

Denmark. jrm@dadlnet.dk

Accepted for publication 26 February 2001
Methods-Expression of NOS isoforms was quantified by western blotting. Inducible NOS (iNOS) and nitrotyrosine were localised by immunohistochemistry. Modulation of NOS activity by topical $N^{\mathrm{G}}$-monomethyl-L-arginine (L-NMMA) or $\mathrm{L}$-arginine was assessed during perfusion of whole colon. Plasma and perfusate nitrite/nitrate $\left(\mathrm{NO}_{\mathrm{x}}\right)$ was measured by Griess' reaction.

Results-Both in collagenous and ulcerative colitis, expression of iNOS was $10^{2}-10^{3}$ higher $(p<0.001)$ than in uninflamed bowel and localised primarily to the epithelium. Endothelial NOS was evenly expressed in all groups while neuronal NOS was undetectable. Nitrotyrosine was markedly expressed in active ulcerative colitis but rarely detected in collagenous colitis and never in uninflamed bowel. In collagenous colitis, the output of $\mathrm{NO}_{\mathrm{x}}$ was markedly increased compared with uninflamed bowel (283 (58) $v<37 \mathrm{nmol} / \mathrm{min}$; $\mathbf{p}<0.01$ ) and fluid was net secreted. L-NMMA reduced the output of $\mathrm{NO}_{x}$ by $13-66 \%$ (95\% confidence intervals) and secretion of fluid by $25-109 \%$ whereas L-arginine increased the output of $\mathrm{NO}_{x}$ by $3-39 \%$ and secretion of fluid by $15-93 \%$.

Conclusions-In collagenous colitis, as opposed to ulcerative colitis, upregulation of iNOS occurs in the absence of nitrotyrosine formation and mucosal damage. Excess generation of NO may be the primary cause of diarrhoea in this condition.

(Gut 2001;49:387-394)
Keywords: colitis; ulcerative colitis; collagenous colitis; inflammatory bowel diseases; large intestine; nitric oxide; nitric oxide synthase

Collagenous colitis is a rare form of idiopathic colitis characterised by chronic watery diarrhoea and microscopic inflammation. ${ }^{1} \mathrm{Al}-$ though the inflammatory mediators responsible for secretion remain undefined, recent studies in collagenous colitis suggest that nitric oxide (NO) is produced in excess by the colonic epithelium. ${ }^{23}$

$\mathrm{NO}$ is generated by the enzyme NO synthase (NOS) which has three distinct isoforms: two constitutively expressed forms (commonly designated cNOS) and an inducible form (iNOS or NOS II). All isoforms require the amino acid L-arginine and oxygen as substrates, in addition to a variety of cofactors. ${ }^{4}$

cNOS exists as neuronal (nNOS or NOS I) and endothelial (eNOS or NOS III) NOS isoforms which show considerable structural similarities. While their names reflect the cell types in which they were originally identified, these enzymes have now been localised in a large number of cell types and tissues and are continuously expressed in the gut by neuronal cell bodies present in the myenteric plexus and in endothelial cells of submucosal vessels. cNOS generates physiological concentrations of NO which serve as a non-adrenergic non-cholinergic neurotransmitter or as a vasodilator. $^{56}$ The enzyme is also expressed in enterocytes ${ }^{7}$ where $\mathrm{NO}$ is thought to modulate colonic ion transport ${ }^{8}$ and host defence mechanisms. ${ }^{9}$

Expression of iNOS is induced in inflammatory cells and enterocytes by various microorganisms, lipopolysaccharides, and proinflammatory cytokines, such as interleukin $1 \beta$, interferon $\gamma$, and tumour necrosis factor $\alpha .^{10}$ Conflicting data in the literature provide evidence of proinflammatory as well as protective properties of NO produced by iNOS. ${ }^{11}{ }^{12}$

Abbreviations used in this paper: cNOS, constitutive nitric oxide synthase; EDTA, ethylene diamine tetra-acetic acid; eNOS, endothelial nitric oxide synthase; GAPDH, glyceraldehyde 3-phosphate dehydrogenase; IgG, immunoglobulin G; iNOS, inducible nitric oxide synthase; L-NMMA,

$N^{\mathrm{G}}$-monomethyl-L-arginine; nNOS, neuronal nitric oxide synthase; NO, nitric oxide; NOS, nitric oxide synthase; $\mathrm{NO}_{x}$, nitrite/nitrate; PBS, phosphate buffered saline. 
In ulcerative colitis, iNOS is considered to be responsible for greatly increased production of $\mathrm{NO}$ in the inflamed colonic mucosa. ${ }^{13-15}$ iNOS appears to be expressed in the epithelium and in foci of inflammation in association with nitrotyrosine ${ }^{16}$ which is the stable end product of the reaction between tyrosine containing cellular proteins and reactive nitrogen species. ${ }^{17}$ Demonstration of nitrotyrosine associated iNOS activity supports the hypothesis that reactive nitrogen species rather than NO per se may be responsible for iNOS induced cellular injury. ${ }^{18}$

In collagenous colitis, diarrhoea is associated with excess production of $\mathrm{NO}$ in the absence of mucosal injury ${ }^{2}$ and in the normal human colon NO donors act as secretagogues to induce secretion of fluid and electrolytes. ${ }^{19}$ Increased production of NO may therefore contribute to diarrhoea in colonic inflammation while nitrotyrosine associated NOS activity may add to mucosal damage.

In the present study, we compared expression of NOS isoenzymes and nitrotyrosine in colonic mucosal biopsies from patients with collagenous colitis with that observed in active ulcerative colitis and uninflamed bowel. The effects on colonic nitrite/nitrate $\left(\mathrm{NO}_{\mathrm{x}}\right)$ output and net fluid transfer of manipulating NO production were determined by "steady state" perfusion of whole colon in patients with collagenous colitis.

\section{Patients and methods PATIENTS}

Permission for the study was obtained from the regional ethics committee and all participants gave informed written consent. Patient characteristics are given in table 1. Patients referred for endoscopy for symptoms of irritable bowel syndrome or haematochezia to exclude colorectal cancer served as controls if they had a normal colonoscopy and uninflamed mucosa at histopathological examination. Patients with an established diagnosis of collagenous colitis, based on typical histopathological features, ${ }^{1}$ were included if they had experienced diarrhoea (stool volume $>300 \mathrm{ml}$ ) on at least three consecutive days during the week prior to endoscopy. All medication was discontinued at least two weeks prior to the study. Patients with relapsing ulcerative colitis were included if they had moderate to severe endoscopic disease activity at routine examination and had received no topical treatment or systemic corticosteroids within the past month or immunosuppressive drugs within the past three months. Oral 5-aminosalicylic acid at a daily dose of
2-4 g was allowed if no change in medication had been made in the last two weeks prior to the investigation. Stool cultures and microscopy were performed in all patients with colitis to detect pathogens, including Clostridium difficile, and all were negative.

\section{ENDOSCOPY}

\section{Preparation}

Patients were studied after a 12 hour fast. Two hours prior to sigmoidoscopy, patients were prepared with an enema consisting of docusate sodium (1 mg) and sorbitol (250 mg) dissolved in $240 \mathrm{ml}$ of sterile water. Prior to colonoscopy, oral bisacodyl was given for two days (10 $\mathrm{mg} /$ day) in addition to metoclopramide (10 $\mathrm{mg}$ ) and a polyethylene glycol 3000 solution (96 $\mathrm{g}$ dissolved in $1.5 \mathrm{l}$ of tap water) the night before. Blood was sampled from a cubital vein before endoscopy and plasma was stored at $-20^{\circ} \mathrm{C}$ for analysis of $\mathrm{NO}_{\mathrm{x}}$ concentrations.

\section{Biopsy}

In patients with uninflamed bowel and collagenous colitis, two biopsy specimens were taken with Radial Jaw biopsy forceps (Microvasive, Watertown, Massachusetts, USA) from the ascending colon for histopathology/ immunohistochemistry and western blot analysis, respectively. In patients with collagenous colitis, additional biopsies were taken from the caecum, transverse colon, descending colon, sigmoid colon, and rectum to define the extent of disease by histopathology. In patients with ulcerative colitis, endoscopic disease activity was assessed during sigmoidoscopy or colonoscopy according to a four point semiquantitative grading system ${ }^{20}$ : inactive $\left(\mathrm{E}_{0}\right)$, mild $\left(\mathrm{E}_{1}\right)$, moderate $\left(\mathrm{E}_{2}\right)$, or severe $\left(\mathrm{E}_{3}\right)$. Two biopsy specimens were taken from the site of maximum inflammation for histopathology/immunohistochemistry and western blot analysis, respectively.

REAGENTS AND ANTIBODIES

Reagents were purchased from Sigma Chemical Company (St Louis, Missouri, USA) unless otherwise stated. iNOS was detected by the use of a rabbit antihuman iNOS antibody (NO-53; a gift from Merck Research Laboratories, Rahway, New Jersey, USA). This antibody was raised against the seven carboxy terminal amino acids of human iNOS and has previously been characterised. ${ }^{16}$ Due to the occurrence of unspecific staining in preliminary studies, immunoglobulin G (IgG) was isolated from the NO-53 rabbit serum by column separation (HiTrap Protein G Sepharose; Amersham Pharmacia Biotech, Little Chalfont,

Table 1 Patient characteristics and concentrations of $\mathrm{NO}_{x}$ in plasma from patients with collagenous colitis, ulcerative colitis, or uninflamed bowel

\begin{tabular}{|c|c|c|c|c|c|c|c|c|c|c|c|c|c|c|c|c|}
\hline \multirow[b]{2}{*}{ Diagnosis } & \multirow[b]{2}{*}{$n$} & \multirow{2}{*}{$\begin{array}{l}\operatorname{Sex} \\
(M / F)\end{array}$} & \multirow{2}{*}{$\begin{array}{l}\text { Age } \\
\text { (y) }\end{array}$} & \multicolumn{2}{|c|}{$\begin{array}{l}\text { Colonic } \\
\text { involvement }\end{array}$} & \multicolumn{4}{|c|}{$\begin{array}{l}\text { Endoscopic activity } \\
\text { score }\end{array}$} & \multicolumn{4}{|c|}{$\begin{array}{l}\text { Histological activity } \\
\text { score }\end{array}$} & \multirow{2}{*}{$\begin{array}{l}24 \text { h stool } \\
\text { volume ( } \mathrm{ml})\end{array}$} & \multirow{2}{*}{$\begin{array}{l}\text { Oral } \\
\text { 5- } A S A\end{array}$} & \multirow{2}{*}{$\begin{array}{l}\text { Plasma } N O_{x} \\
(\mu M)\end{array}$} \\
\hline & & & & $P S$ & Extensive & $E_{0}$ & $E_{1}$ & $E_{2}$ & $E_{3}$ & $H_{0}$ & $H_{1}$ & $\mathrm{H}_{2}$ & $H_{3}$ & & & \\
\hline Collagenous colitis & 8 & $2 / 6$ & $70(3)$ & 0 & 8 & 8 & 0 & 0 & 0 & - & & & & $687(112)$ & 0 & $111(20)^{\star \star}$ \\
\hline Ulcerative colitis & 9 & $4 / 5$ & $34(3)^{\star}$ & 4 & 5 & 0 & 0 & 5 & 4 & 0 & 0 & 6 & 3 & - & 4 & $82(9)^{\star \star}$ \\
\hline Uninflamed bowel & 10 & $6 / 4$ & $55(7)^{\star}$ & - & - & 10 & 0 & 0 & 0 & 10 & 0 & 0 & 0 & - & 0 & $27(2)$ \\
\hline
\end{tabular}

Values represent number of patients unless otherwise stated. In ulcerative colitis, disease activity was defined endoscopically $\left(\mathrm{E}_{0}-\mathrm{E}_{3}\right)$ and histologically $\left(\mathrm{H}_{0}-\mathrm{H}_{3}\right)$.

5-ASA, 5-aminosalicylic acid; Extensive, left sided colitis or pancolitis; $\mathrm{NO}_{\mathrm{x}}$, nitrite/nitrate; PS, proctosigmoiditis.

${ }^{\star} \mathrm{p}<0.05$ compared with collagenous colitis; ${ }^{\star \star} \mathrm{p}<0.001$ compared with uninflamed bowel. 
UK). The specificity of the iNOS IgG antibody for human iNOS was determined by use of a peptide containing a seven amino acid sequence identical to that of the carboxy terminal end of human iNOS $\left(\mathrm{H}_{2} \mathrm{~N}-\mathrm{Tyr}-\mathrm{Arg}-\mathrm{Ala}-\mathrm{Ser}-\mathrm{Leu}-\mathrm{Glu}-\right.$ Met-Ser-Ala-Leu-COOH; Merck). For detection of cNOS, a monoclonal mouse antihuman eNOS antibody (No N30020; Transduction Laboratories, Lexington, Kentucky, USA) and a monoclonal mouse antihuman nNOS antibody (No N31020; Transduction) were used. For detection of nitrotyrosine, a polyclonal rabbit antinitrotyrosine antibody (No 06-284; Upstate Biotechnology Inc, Lake Placid, New York, USA) was used. Glyceraldehyde 3-phosphate dehydrogenase (GAPDH) was detected with a monoclonal mouse antirabbit GAPDH antibody (No TRK5G4-6C5; Research Diagnostics Inc., Flanders, New Jersey, USA).

$N^{\mathrm{G}}$-monomethyl-L-arginine acetate (LNMMA) and L-arginine hydrochloride were purchased from Clinalfa (Läufelfingen, Switzerland).

\section{WESTERN BLOT ANALYSIS}

Handling and lysis of biopsies

Immediately after sampling the biopsy specimens were rinsed in icecold saline, placed in vials with Dulbecco's phosphate buffered saline (PBS), and frozen in liquid nitrogen for storage at $-70^{\circ} \mathrm{C}$. The biopsies were lysed in icecold lysis buffer (50 mM Tris $\mathrm{HCl}, \mathrm{pH} 7.4,150 \mathrm{mM}$ $\mathrm{NaCl}, 1 \%$ (v/v) NP-40 (ICN, Costa Mesa, California, USA), $0.25 \% \quad(\mathrm{w} / \mathrm{v}) \quad \mathrm{Na}-$ deoxycholate, $1 \mathrm{mM} \mathrm{Na} \mathrm{VO}_{4}, 1 \mathrm{mM} \mathrm{NaF}, 1$ $\mathrm{mM}$ phenylmethylsulphonyl fluoride, $1 \mathrm{mM}$ ethylene diamine tetra-acetic acid (EDTA) (Life Technologies, Gaithersburg, Maryland, USA), and 1 Complete tablet $/ 50 \mathrm{ml}$ (Boehringer Mannheim, Mannheim, Germany)) for 24 hours on ice. Samples were sonicated and centrifuged at $20000 \mathrm{~g}$ for 30 minutes at $4^{\circ} \mathrm{C}$. Supernatants were stored at $-70^{\circ} \mathrm{C}$ until analysis and protein content was determined using the method of Lowry. ${ }^{21}$

\section{Electrophoresis and blotting}

Whole cell lysates (20 $\mu \mathrm{g}$ of sample protein) were boiled for five minutes in loading buffer (62.5 $\mathrm{mM}$ Tris $\mathrm{HCl}, \mathrm{pH} 6.8,10 \%$ (v/v) glycerol, $2 \%$ $(\mathrm{w} / \mathrm{v})$ sodium dodecyl sulphate, $0.025 \%(\mathrm{w} / \mathrm{v})$ bromphenol blue, and $10 \% \quad(\mathrm{v} / \mathrm{v})$ 2-mercaptoethanol) prior to loading on 4-12\% polyacrylamide gels (Novex, San Diego, California, USA). To enable relative quantification, a "reference lysate" (colonic mucosa from the free margin of a rectal carcinoma resection) was loaded on each gel. After electrophoresis proteins were transferred onto polyvinylidene fluoride membranes (Hybond-P; Amersham), as described by the manufacturer. The membranes were washed with PBS-T, pH $7.4(80 \mathrm{mM}$ $\mathrm{NaH}_{2} \mathrm{PO}_{4}$ (ICN), $20 \mathrm{mM} \mathrm{Na} \mathrm{HPO}_{4}$ (ICN), 100 $\mathrm{mM} \mathrm{NaCl}$, and $0.05 \%$ (w/v) Tween-20) before incubation in a blocking solution (PBS-T and $5 \%(\mathrm{w} / \mathrm{v})$ non-fat dry milk). Immunodetection was performed using the ECL System (Amersham) with the anti-iNOS (final dilution 1:10 000), anti-eNOS (1:2500), anti-nNOS (1:2500), or anti-GADPH (1:50 000) primary antibodies followed by antirabbit or antimouse secondary antibodies $(1: 4000)$ linked to horseradish peroxidase (Kirkegaard and Perry Laboratories, Gaithersburg, Maryland, USA). Prior to reprobing, membranes were stripped of antibodies by submersion in stripping buffer (100 $\mathrm{mM}$ 2-mercaptoethanol, 2\% (w/v) sodium dodecyl sulphate, and $62.5 \mathrm{mM}$ Tris $\mathrm{HCl}, \mathrm{pH}$ 6.7), incubated for 30 minutes at $60^{\circ} \mathrm{C}$ at constant agitation, and washed in PBS-T. The size of the detected proteins was estimated with a molecular weight marker (SeeBlue Standard; Novex). To enable relative quantification of low and high grade antibody binding, two to four radiographs (Hyperfilm ECL; Amersham) were processed for each membrane with a variable time of exposure. On each radiograph, the densitometric value of protein bands was read relative to the density of the "reference lysate", which was defined as 1.0 (GeneGenius Gel Documentation System, Syngene, Cambridge, $\mathrm{UK})$.

To perform blocking experiments, iNOS antibody was preincubated with $1 \mu \mathrm{g} / \mu \mathrm{l}$ human iNOS peptide for three hours at room temperature prior to incubation with stripped membranes. Binding of the eNOS antibody to human eNOS was established using human endothelial cell culture lysate (Transduction). Binding of the nNOS antibody to human nNOS was determined using lysates of a biopsy from human cerebellum collected at autopsy. ${ }^{22}$

HISTOPATHOLOGY AND IMMUNOHISTOCHEMICAL ANALYSIS

The biopsy specimens were fixed in $4 \%(\mathrm{v} / \mathrm{v})$ formaldehyde for four hours and embedded in paraffin. Deparaffinised sections were stained with haematoxylin and eosin and examined by a pathologist unaware of the immunochemical results. In ulcerative colitis, histological inflammatory activity was assessed according to a four point semiquantitative grading scale: inactive $\left(\mathrm{H}_{0}\right)$, mild $\left(\mathrm{H}_{1}\right)$, moderate $\left(\mathrm{H}_{2}\right)$, or severe $\left(\mathrm{H}_{3}\right){ }^{20}$

Immunohistochemical analysis was performed using deparaffinised sections from the same biopsies. Sections were boiled in $10 \mathrm{mM}$ citrate buffer, $\mathrm{pH}$ 6.0, for 10 minutes and treated with 3\% (w/v) hydrogen peroxide for another 10 minutes. The optimum dilution for the primary antibodies was assessed in titration experiments (twofold dilutions $1: 1000$ to $1: 128000$, with $2 \%$ $(\mathrm{v} / \mathrm{v})$ bovine serum in Tris buffered saline incubated for 16 hours at $4^{\circ} \mathrm{C}$ ). Tissue bound primary antibody was detected by incubation with biotinylated goat antimouse/rabbit IgG antibody 1:500 and a complex of streptavidin and biotinylated horseradish peroxidase (Duet Kit; Dako, Glostrup, Denmark). Development was performed with $0.04 \%$ (w/v) 3-amino-9ethylcarbazole and sections were counterstained with haematoxylin.

The optimum dilution for the iNOS IgG antibody was found to be 1:8000. Blocking experiments for iNOS labelling were performed as outlined above. In addition, sections were processed without the iNOS IgG antibody or with an irrelevant primary antibody (5 $\mu \mathrm{g} / \mathrm{ml}$ rabbit antifluorescein isothiocyanate antibody (Dako)). The optimum dilution of 
the nitrotyrosine antibody was 1:1000. Sections from uninflamed bowel treated with 10 $\mu \mathrm{M}$ peroxynitrite (Upstate) for one hour at room temperature served as positive controls. In additional experiments the nitrotyrosine antibody was preincubated with $10 \mu \mathrm{M}$ 3-nitro-L-tyrosine at room temperature before incubation of sections.

PERFUSION OF WHOLE COLON

"Steady state" perfusion of whole colon was performed as previously described ${ }^{23}$ in six patients with uninflamed bowel and in six patients with collagenous colitis following endoscopic intubation of the colon. The tip of a 2.3 $\mathrm{mm}$ (ID) Teflon tube (W Cook Europe, Bjaeverskov, Denmark) was placed in the caecum via the biopsy channel of an Olympus CF-1T100L colonoscope. The position of the tube was checked fluoroscopically before and after perfusion. The test solution (145 mM $\mathrm{NaCl}, \mathrm{pH} 7.4,37^{\circ} \mathrm{C}$, and $20 \mu \mathrm{Ci} / 1^{51} \mathrm{Cr}$-EDTA (Amersham) as a non-absorbable marker) was infused into the caecum at a rate of $15 \mathrm{ml} / \mathrm{min}$ using a volumetric pump (2115 Multiperpex pump; LKB Products AB, Bromma, Sweden). After a 60 minute equilibration period, perfusates were continuously collected through a CH 25 rectal tube (Pharma-Plast International, Lynge, Denmark) and pooled on ice at 15 minute intervals for 90 minutes (basal period).

In patients with collagenous colitis, $750 \mathrm{mg}$ of L-NMMA dissolved in the same test solution $(\mathrm{pH} 7.4)$ was subsequently infused into the caecum over a two minute period for competitive inhibition of NOS enzymes. Although the initial concentration of L-NMMA $(25 \mathrm{mg} / \mathrm{ml}$ $\sim 100 \mathrm{mM}$ ) administered was diluted into the fluid volume of the perfused colon (approximately $300 \mathrm{ml})^{24}$ and by the test solution subsequently infused, the mucosa of all segments of the colon was shortly exposed to concentrations of L-NMMA sufficiently high to cause maximal inhibition of NOS $\left(\mathrm{ID}_{50}\right.$ $\left.3-7 \times 10^{-6} \mathrm{M}\right),{ }^{25}$ at least during part of the equilibration period (60 minutes). Perfusion with test solution was continued for another 150 minutes (experimental period 90 minutes).

Repeat perfusion was performed within 21-240 days (range) using $750 \mathrm{mg}$ of L-arginine for stimulation of NO production.

In patients with uninflamed bowel, time control experiments were performed by infusing test solution into the caecum instead of L-NMMA or L-arginine at the start of the experimental period.

Samples of the perfusates were stored at $-20^{\circ} \mathrm{C}$ for analysis of $\mathrm{NO}_{\mathrm{x}} \cdot{ }^{51} \mathrm{Cr}$ activity was assessed by $\gamma$-spectrometry (Model 1185; Searl Nuclear, Chicago, Illinois, USA).

$\mathrm{NO}_{\mathrm{x}}$ IN PLASMA AND COLONIC PERFUSATES

In samples of plasma and perfusates, concentrations of $\mathrm{NO}_{\mathrm{x}}$ were determined by the method of Griess after enzymatic conversion of nitrate to nitrite. ${ }^{26}$ Briefly, $200 \mu \mathrm{l}$ of sample (undiluted or twofold diluted with distilled water) was incubated with $80 \mathrm{mM} \mathrm{K} \mathrm{K}_{2} \mathrm{HPO}_{4}$ / $\mathrm{KH}_{2} \mathrm{PO}_{4}, 50 \mu \mathrm{M}$ NADPH, $5 \mu \mathrm{M}$ FAD, and 200 $\mathrm{U} / 1$ nitrate reductase (Boehringer Mannheim).
NADPH excess was eliminated by $10 \mathrm{mg} / 1$ lactate dehydrogenase (Boehringer Mannheim) and $10 \mathrm{mM}$ sodium pyruvate. Proteins were precipitated in $15 \mathrm{~g} / 1 \mathrm{ZnSO}_{4}$, and after centrifugation at $3000 \mathrm{~g}$ for 30 minutes a volume of supernatant was incubated with Griess' reagent $(0.125 \mathrm{~g} / \mathrm{l}$ sulphanilamide (Merck, Darmstadt, Germany), $12.5 \mathrm{mg} / \mathrm{l}$ $N$-1-naphthyl-ethylenediamine, and $3.12 \mathrm{~g} / 1$ phosphoric acid) for 10 minutes at room temperature. All reactions were carried out in duplicate. Absorbance was measured at 540 $\mathrm{nm}$ and sodium nitrate, diluted in distilled water in the range $0-50 \mu \mathrm{M}$, was used for calibration. The detection limit, defined as the mean value of procedure blanks +2 SDs $(n=24)$, was $2.5 \mu M$ and the interassay variation was $12.6 \%$ at $7.4 \mu M(n=24)$ and $4.9 \%$ at $40 \mu M \quad(n=24)$. Measurements of nitrate standards were unaffected by addition of L-NMMA or L-arginine.

\section{CALCULATIONS AND STATISTICS}

Colonic output of $\mathrm{NO}_{x}$ and rates of net fluid transfer were calculated using standard formulas as the mean of three consecutive 15 minute values obtained at "steady state" - that is, coefficients of variation in rectal recovery of ${ }^{51} \mathrm{Cr}$ activity less than $3 \%$ in individual perfusion experiments during basal periods or after caecal infusion of L-NMMA or L-arginine (experimental period). ${ }^{23}$ Luminal output of $\mathrm{NO}_{\mathrm{x}}$ and net secretion of fluid were indicated by a positive sign and net absorption of fluid by a negative sign.

Results are expressed as mean (SEM) or as 95\% confidence intervals where appropriate. The normality assumption for this model was tested with the Komolgorov-Smirnov statistics, the Levine statistics were used to test for equal variance, and data were analysed by the Student's $t$ test for paired or unpaired variables, where appropriate. ${ }^{27}$ For some of the end points, the normality assumption was violated. Thus the Mann-Whitney U test for unpaired variables was performed to corroborate the parametric analysis test. Values of $p$ less than 0.05 (two tailed) were considered significant.

\section{Results}

DISEASE ACTIVITY

Patients with uninflamed bowel showed a normal mucosa at endoscopy and histology. Also patients with collagenous colitis had a normal endoscopy but all showed histopathological changes characteristic of collagenous colitis throughout the colon and in the rectum (table 1). Patients with ulcerative colitis had moderate to severe disease activity at endoscopy and histopathology.

EXPRESSION OF iNOS, eNOS, AND nNOS

Mucosal cell lysates from all patients with uninflamed and inflamed bowel showed a single protein band at the $130 \mathrm{kDa}$ position in the western blot analysis with the iNOS IgG antibody (fig 1). Values of band densities relative to the colonic "reference lysate" were significantly higher $(\mathrm{p}<0.001)$ in the groups of patients with collagenous colitis (150 (21); 

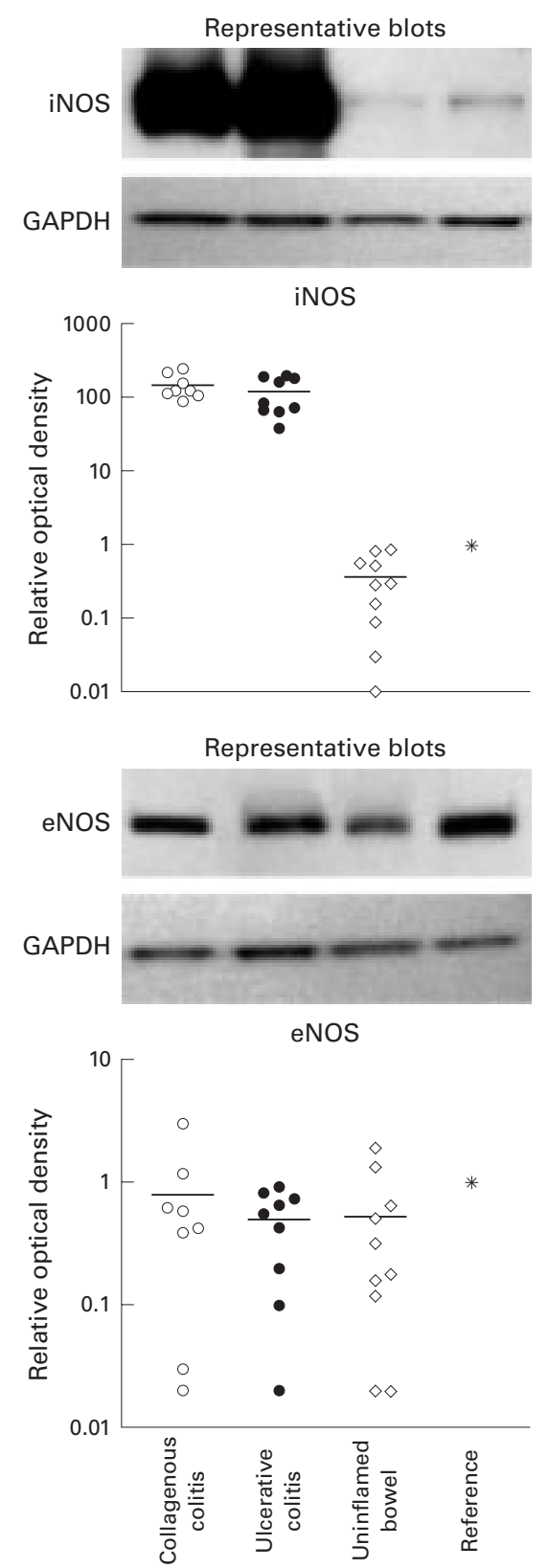

Figure 1 Expression of inducible nitric oxide synthase (iNOS) and endothelial nitric oxide synthase (eNOS) in mucosal biopsies from patients with collagenous colitis, active ulcerative colitis, or uninflamed bowel. Expression was analysed by western blotting and quantified by densitometry relative to a reference, which was defined as 1.0. For internal control of loading, samples were also blotted against anti-glyceraldehyde 3-phosphate dehydrogenase (GAPDH) antibody. In the scatterplots, the logarithmic y axes define individual values with group means displayed as horizontal lines.

mean (SEM)) and ulcerative colitis (123 (22)) than in the group of patients with uninflamed bowel $(0.4(0.1))$. There were no statistically significant differences $(p=0.27)$ in band densities between the two groups of colitis patients (fig 1). Staining was not observed after preincubation of the iNOS antibody with the human iNOS peptide, indicating that the detected band represents iNOS.

Following application of the eNOS antibody, a single protein band was detected in the 140 $\mathrm{kDa}$ area (fig 1). There were no differences in optical densities of the eNOS bands between patients with uninflamed bowel and patients with collagenous or ulcerative colitis $(p=0.56$ and $\mathrm{p}=0.91$, respectively).

The nNOS western blot analyses revealed no protein bands except for that of the nNOS standard and a single protein band from the lysate of human cerebellum at the $155 \mathrm{kDa}$ position (data not shown), demonstrating the ability of the antibody to bind with human nNOS.

LOCALISATION OF INOS AND NITROTYROSINE

Mucosal biopsy specimens from six of the 10 patients with uninflamed bowel showed minimal labelling in the crypt epithelium with the iNOS IgG antibody. In biopsy specimens from all patients with collagenous colitis, the reaction product of the iNOS antibody was localised in the epithelial cells of the colonic mucosa but intense staining was observed only at the luminal border (fig 2). Inflammatory cells in the lamina propria produced negligible staining. In biopsy specimens from all patients with ulcerative colitis, the reaction product of the iNOS antibody was localised within the epithelial cells and in areas with less intense epithelial staining within the apical cytoplasm (fig 2). In general, labelling was less pronounced in crypt cells and lamina propria inflammatory cells. Staining was absent if the iNOS IgG antibody was preincubated with the human iNOS peptide and if samples were processed with an irrelevant primary antibody or without the iNOS IgG antibody.

Nitrotyrosine was not observed in biopsies from patients with uninflamed bowel and labelled only slightly in the epithelium from a single patient with collagenous colitis. Intense epithelial staining was observed in all biopsies from patients with active ulcerative colitis $(\mathrm{p}<0.01)$ (see fig 3) and was associated with the presence of neutrophils in the epithelium. In areas of the epithelium with less intense staining, neutrophils were fewer or absent. Nitrotyrosine was also detected in clusters of mononuclear cells from three patients with collagenous colitis and in lamina propria inflammatory cells which were predominantly neutrophils from six of the nine patients with ulcerative colitis (see fig 3 ) but was absent if the nitrotyrosine antibody was preincubated with 3-nitro-L-tyrosine. Tissues from uninflamed bowel pretreated with peroxynitrite produced intense staining which was inhibited by preincubation of the antibody with 3-nitro-Ltyrosine.

PLASMA CONCENTRATIONS OF $\mathrm{NO}_{x}$ Concentrations of $\mathrm{NO}_{\mathrm{x}}$ in plasma were threefold higher $(p<0.001)$ in patients with collagenous or ulcerative colitis than in patients with uninflamed bowel (table 1).

EFFECTS OF L-NMMA OR L-ARGININE ON COLONIC OUTPUT OF $\mathrm{NO}_{\mathrm{x}}$ AND NET FLUID TRANSFER In patients with uninflamed bowel, concentrations of $\mathrm{NO}_{\mathrm{x}}$ in the perfusates were below the detection limit. Fluid was absorbed and net transfer rates of fluid were unaffected $(-2.1$ (0.2) $v-2.1(0.2) \mathrm{ml} / \mathrm{min}$; mean (SEM), 

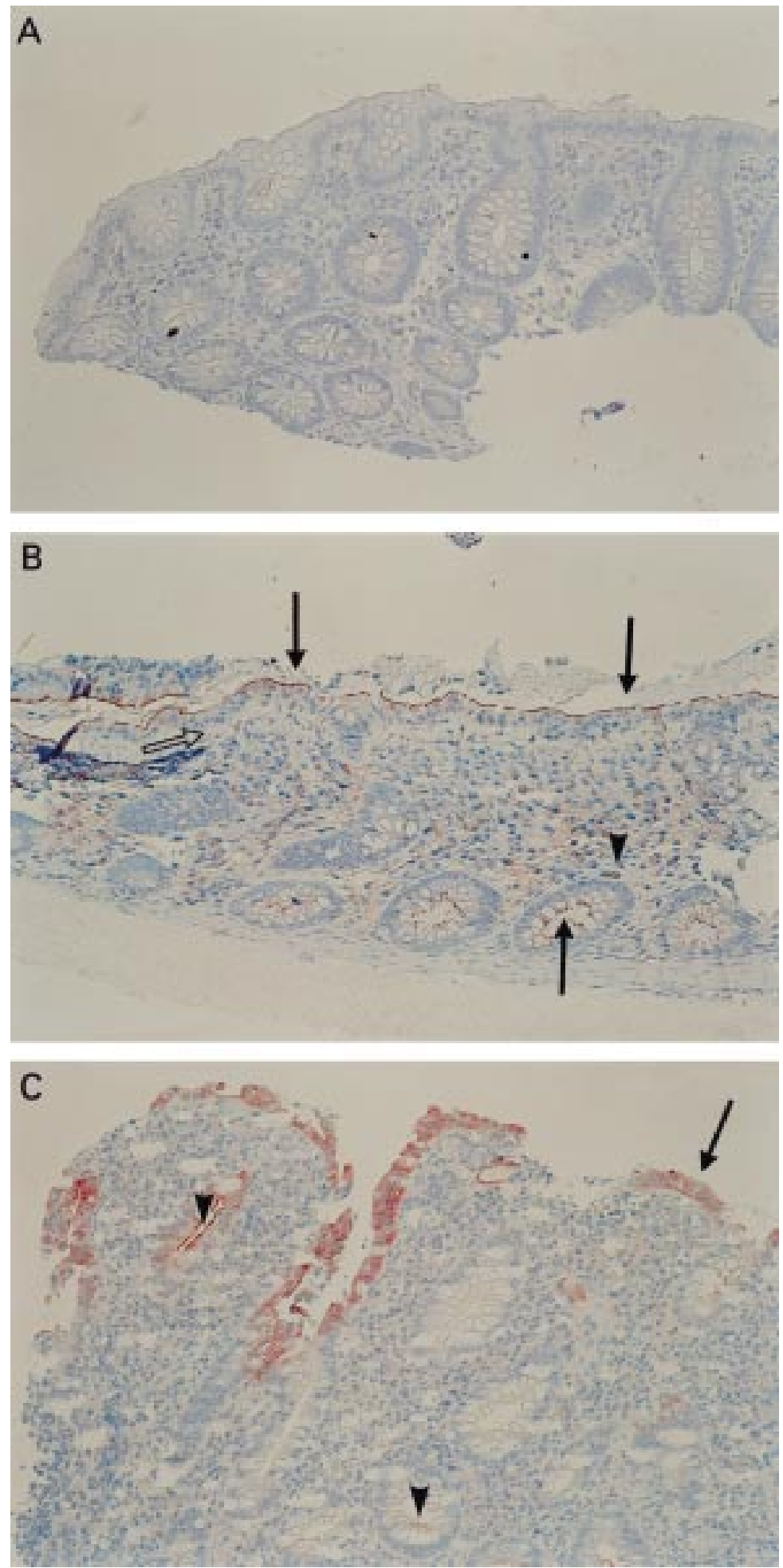

Figure 2 Localisation of inducible nitric oxide synthase (iNOS) in mucosal biopsies from human colon analysed by immunohistochemistry and counterstained with haematoxylin. $(A)$ Uninflamed mucosa stained with iNOS IgG antibody (see text). No reaction was observed. (B) Biopsy section from a collagenous colitis patient showing a thickened collagenous band beneath the epithelium (open arrow). The reaction product (red) of $i N O S$ antibody is localised at the luminal border of the epithelial cells (see arrows at surface and crypts) and to a minor degree in lamina propria mononuclear cells (arrowhead). (C) Biopsy from a patient with severe ulcerative colitis at endoscopy showing disturbed mucosal architecture and pronounced infiltration of inflammatory cells. The reaction product of the iNOS antibody is localised primarily in the surface epithelial cells (arrow). A discrete reaction is observed in adjacent neutrophils and in mononuclear cells of the lamina propria. In areas with less intense reaction this is primarily localised in the apical cytoplasm (arrowheads).

$\mathrm{p}=0.89)$ by duration of perfusion $(60-300$ minutes) in time control experiments.
Among patients with collagenous colitis, one refused to participate in the second perfusion (L-arginine). Colonic $\mathrm{NO}_{\mathrm{x}}$ output was markedly higher in patients with collagenous colitis than in patients with uninflamed bowel $(283(58) v<37$ $\mathrm{nmol} / \mathrm{min} ; \mathrm{p}<0.01$ ) and fluid was net secreted into the colonic lumen (basal period; see table 2). L-NMMA significantly reduced the concentration of $\mathrm{NO}_{\mathrm{x}}$ in the perfusates $(18.5$ (3.5) $v$ 12.1 (3.2) $\mu \mathrm{M} ; \mathrm{p}=0.02$ ), the output of $\mathrm{NO}_{\mathrm{x}}$ by $40 \%$ (283 (58) v 171 (43) nmol/min; $\mathrm{p}<0.01$ ), and net secretion of fluid by approximately $70 \%$ (0.67 (0.16) $v 0.22(0.18) \mathrm{ml} / \mathrm{min} ; \mathrm{p}<0.01)$ (see table 2). In contrast, L-arginine significantly increased the concentration of $\mathrm{NO}_{\mathrm{x}}$ in the perfusates (11.1 (2.8) v 14.1 (3.0) $\mu \mathrm{M} ; \mathrm{p}=0.03)$, the output of $\mathrm{NO}_{\mathrm{x}}$ by $20 \%$ (168 (34) v 203 (33) $\mathrm{nmol} / \mathrm{min} ; \mathrm{p}=0.03)$, and net secretion of fluid by approximately $50 \%(0.50(0.23) v 0.78(0.25)$ $\mathrm{ml} / \mathrm{min} ; \mathrm{p}=0.02$ ) (see table 2 ).

\section{Discussion}

The results of the present study suggest that the activity of NOS in the colonic epithelium from patients with collagenous colitis is upregulated and that iNOS may be the source of increased colonic output and raised plasma concentrations of $\mathrm{NO}_{\mathrm{x}}$. Moreover, alterations in colonic $\mathrm{NO}_{\mathrm{x}}$ output and fluid secretion induced by topical L-NMMA and L-arginine suggest that NO may be the cause of secretion in collagenous colitis or at least contribute to the diarrhoea observed in this condition. Our findings are consistent with previous reports of excess colonic production of $\mathrm{NO}$ gas in collagenous colitis ${ }^{2}$ but the lack of nitrotyrosine expression suggests that this occurs without formation of reactive nitrogen species. Also, the observation of enhanced iNOS expression in active ulcerative colitis accords with previous experience, ${ }^{1628-30}$ and demonstration of nitrotyrosine labelling in the colonic epithelium supports the theory that increased iNOS expression may be associated with excess formation of reactive nitrogen species. ${ }^{16}{ }^{30}$

The properties of the iNOS and nitrotyrosine antibodies used in this study have recently been validated. ${ }^{16}$ The impression of highly specific labelling was confirmed by competitive displacement of the purified antibodies by the human iNOS peptide and nitrotyrosine, respectively. Surprisingly, we observed slight iNOS expression even in uninflamed bowel. This finding may however represent an artefact due to the use of bisacodyl for bowel preparation. ${ }^{31}$ Although the presence of iNOS in epithelial cells of uninvolved mucosa from patients with colorectal cancer has been reported, ${ }^{7}{ }^{32}$ details of prior bowel preparation were not given.

The evenly distributed expression of eNOS in patients with ulcerative colitis and uninflamed bowel agrees with previous experience $^{29}$ while the lack of nNOS expression in mucosal biopsies from all groups of patients may merely reflect the absence of neurones in the superficial mucosal layers.

The pathogenesis of collagenous colitis is largely unknown. As surgical exclusion of the 

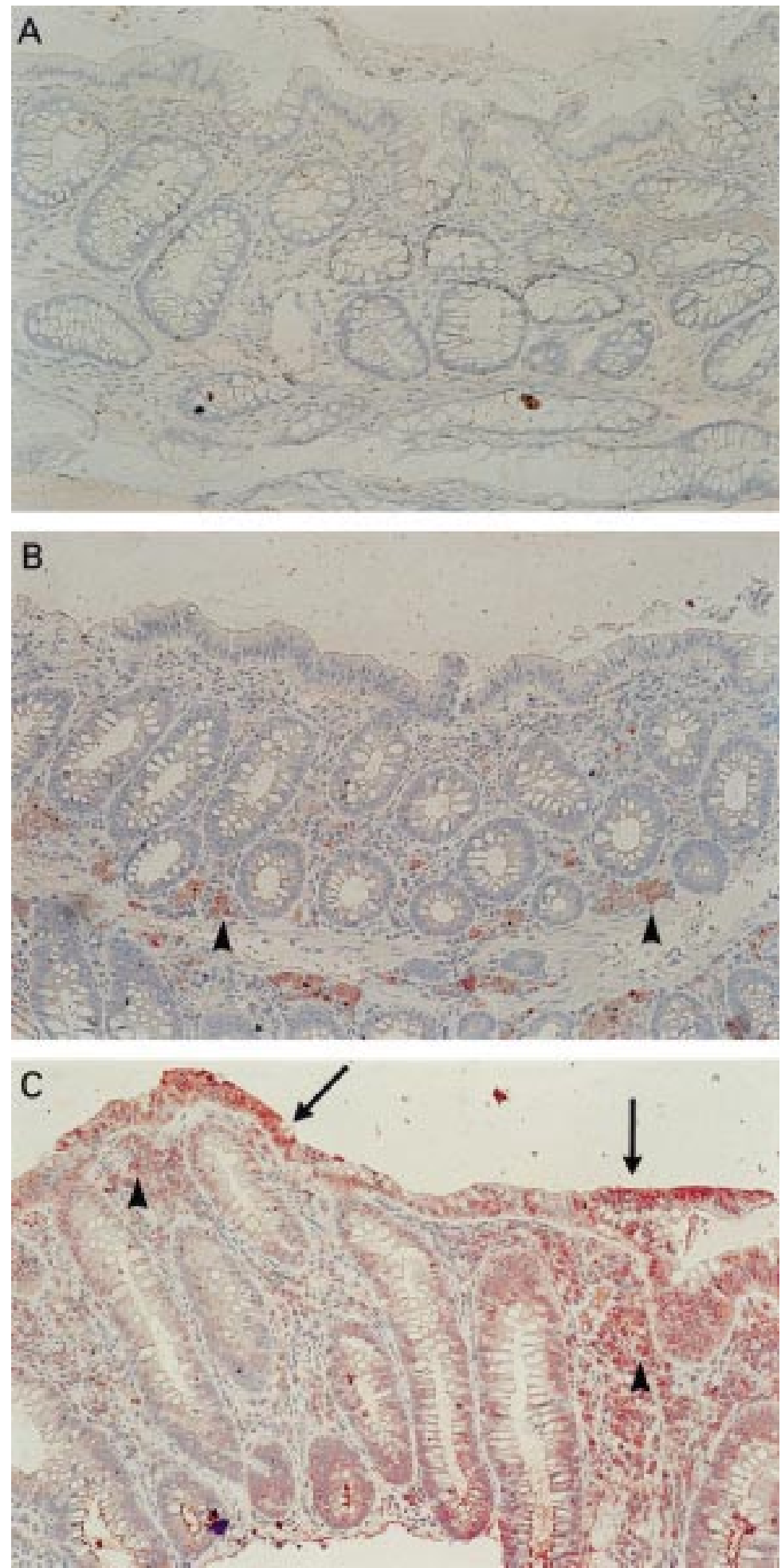

Figure 3 Localisation of nitrotyrosine in mucosal biopsies from human colon analysed by immunohistochemistry and counterstained with haematoxylin. (A) Uninflamed mucosa stained with nitrotyrosine antibody (see text). No reaction was observed. (B) Biopsy section from a patient with collagenous colitis. The reaction product (red) of the nitrotyrosine antibody is observed within mononuclear cells of the lamina propria (arrowheads). (C) Biopsy section from a patient with ulcerative colitis showing disturbed mucosal architecture and pronounced infiltration of inflammatory cells. The reaction product of the nitrotyrosine antibody is localised in the epithelium (arrows) in association with neutrophils and in lamina propria inflammatory cells (arrowheads)

colon by ileostomy induces remission of collagenous colitis ${ }^{33}$ it is likely that one or more unknown luminal factor(s) are responsible for induction of iNOS at the luminal border of the colonic epithelium. Our data indicate that NO generated by iNOS may contribute to epithelial secretion and watery diarrhoea in this variant form of colitis. Although the data conflict with those obtained in rodents, ${ }^{8}$ they agree with previous observations made in Ussing chamber preparations of human colon, indicating secretory actions of NO in the large bowel. ${ }^{19}$ The partial response in $\mathrm{NO}_{\mathrm{x}}$ output and net fluid transport rates observed in the present study may be explained by concentrations of L-NMMA below those required for maximal inhibition of NOS in the colonic epithelium during the experimental period. Although concentrations of L-NMMA were continuously reduced with time, activities of ${ }^{51} \mathrm{Cr}$ and concentrations of $\mathrm{NO}_{\mathrm{x}}$ were constant in samples of the perfusate collected at the rectum during the 90 minute experimental period (60-150 minutes following infusion of L-NMMA).

Previous observations in animal models have led to the assumption that induction of iNOS in chronic inflammatory bowel disease is an injurious event ${ }^{1134}$ and initiated a search for iNOS inhibitory compounds with antiinflammatory properties. So far, the use of selective iNOS inhibitors in experimental colitis has provided conflicting data. ${ }^{35}{ }^{36}$ While the enhanced anti-inflammatory effects of an NO releasing derivative of mesalamine suggest a protective role of $\mathrm{NO}$ in experimental colitis, ${ }^{37}$ conflicting results obtained in iNOS "knockout" mice emphasise the need for human studies. $^{38} 39$

In ulcerative colitis, mucosal damage is associated with formation of nitrotyrosine which is considered a marker of reactive nitrogen species such as peroxynitrite, nitrous acid, nitryl chloride, or nitrogen dioxide. These compounds may originate in the reaction of iNOS generated NO with reactive oxygen species $^{39}$ or in a myeloperoxidase dependent pathway, ${ }^{40}$ suggesting involvement of neutrophils. In the present study, biopsies from patients with ulcerative colitis showed intense epithelial staining of nitrotyrosine which was associated with infiltration of neutrophils in the epithelium. This finding supports a role for the formation of nitrotyrosine as responsible for the damage observed in ulcerative colitis. This notion is compatible with absence of nitrotyrosine and neutrophils in collagenous colitis. Thus neutrophils characteristically infiltrate the epithelium in ulcerative colitis but are rarely observed in collagenous colitis. ${ }^{41}$ In addition to neutrophils, colonic epithelial cells may produce superoxide, as suggested by preliminary results. ${ }^{42}$

In summary, our results demonstrate that iNOS is upregulated in the colonic epithelium from patients with collagenous colitis and that increased production of NO may be the cause of diarrhoea observed in these patients. The location of iNOS at the mucosal border is compatible with the notion that a luminal factor is responsible for induction of iNOS. The results of this study also confirm enhanced expression of iNOS and nitrotyrosine in the colonic epithelium from patients with active ulcerative colitis and suggest that reactive 
Table 2 Effects of topical $N^{G}$-monomethyl-L-arginine ( $\left.L-N M M A\right)$ and L-arginine (L-Arg) on colonic net fluid transfer and output of nitrite/nitrate $\left(\mathrm{NO}_{x}\right)$ in patients with collagenous colitis during perfusion of whole colon

\begin{tabular}{|c|c|c|c|c|c|c|c|c|c|c|c|c|}
\hline \multirow[b]{2}{*}{ Patient } & \multicolumn{6}{|c|}{ Net fluid transfer ( $\mathrm{ml} / \mathrm{min}$ ) } & \multicolumn{6}{|c|}{ NO ${ }_{x}$ output $($ nmol/min) } \\
\hline & Basal & $L-N M M A$ & $\Delta$ & Basal & $L-A r g$ & $\Delta$ & Basal & $L-N M M A$ & $\Delta$ & Basal & $L-A r g$ & $\Delta$ \\
\hline MS & +0.66 & -0.15 & -0.81 & +0.43 & +0.94 & +0.51 & +132 & +52 & -80 & +93 & +161 & +68 \\
\hline $\mathrm{KL}$ & +0.68 & +0.42 & -0.26 & +0.60 & +0.96 & +0.35 & +161 & +85 & -76 & +188 & +220 & +32 \\
\hline IS & +0.11 & -0.18 & -0.29 & -0.10 & +0.10 & +0.20 & +486 & +356 & -130 & +91 & +115 & +24 \\
\hline IH & +1.31 & +0.82 & -0.49 & +1.31 & +1.51 & +0.20 & +352 & +187 & -165 & +268 & +314 & +46 \\
\hline GF & +0.54 & -0.16 & -0.70 & +0.28 & +0.40 & +0.12 & +187 & +178 & -10 & +199 & +204 & +5 \\
\hline $\mathrm{JK}$ & +0.71 & +0.57 & -0.14 & - & - & - & +379 & +170 & -209 & - & - & - \\
\hline Grand mean & +0.67 & +0.22 & -0.45 & +0.50 & +0.78 & +0.28 & +283 & +171 & -112 & +168 & +203 & +35 \\
\hline
\end{tabular}

Individual and mean (SEM) values are given. Two studies were performed in each patient (with the exception of patient JK), which is why a basal value is given for both L-NMMA and L-arginine treatment. Positive values indicate output of $\mathrm{NO}_{\mathrm{x}}$ or secretion of fluid and negative values indicate absorption.

${ }^{\star} \mathrm{p}<0.01$ or $\mathrm{tp}<0.03$ compared with basal period.

nitrogen species, rather than NO per se, may contribute to mucosal injury.

Part of this study was presented at the Digestive Disease Week 1999, Orlando, Florida, USA. Dr A Perner is the recipient of a research fellowship from the University of Copenhagen. This work was also supported by grants from the Danish ColitisCrohn Foundation. Dr Hollis R Williams, Dr Richard A Mumford, and Dr Jeffrey R Weidner at Merck Research Laboratories, Rahway, New Jersey, kindly donated the NO-53 antibody and the iNOS peptide and gave essential advice for refining of the immunohistochemical assay. We would like to thank Steen Just Justesen for technical assistance with measurements of $\mathrm{NO}_{\mathrm{x}}$.

1 Lindström CG. 'Collagenous colitis' with watery diarrhoea-a new entity? Pathol Eur 1976;11:87-9.

2 Perner A, Hillingsø J, Nordgaard I, et al. Nitric oxide in colonic inflammation: proinflammatory mediator or protective factor? Gut 1997;41:A17.

3 Lundberg JON, Herulf M, Olesen $M$, et al. Increased nitric oxide production in collagenous colitis and lymphocytic colitis. Eur f Clin Invest 1997;27:869-71.

4 Nathan C, Xie QW. Nitric oxide synthases: roles, tolls, and controls. Cell 1994;78:915-8.

controls. Cell 1994;78:915-8.
Hata F, Ishii T, Kanada A, et al . Essential role of nitric oxide in descending inhibition in the rat proximal colon. Biochem in descending inhibition in the rat proxima

6 Moncada S, Palmer RM, Higgs EA. Nitric oxide: physiology, pathophysiology, and pharmacology. Pharmacol Rev 1991;43:109-42

7 Moochhala S, Chhatwal VJ, Chan ST, et al. Nitric oxide synthase activity and expression in human colorectal cancer. Carcinogenesis 1996;17:1171-4.

8 Schirgi DA, Beubler E. Proabsorptive properties of nitric oxide. Digestion 1998;59:400-3.

9 Fang FC. Mechanisms of nitric oxide-related antimicrobial activity. F Clin Invest 1997;99:2818-25.

10 Salzman AL, Denenberg AG, Ueta I, et al. Induction and activity of nitric oxide synthase in cultured human intesti-

11 Whittle BJR. Nitric oxide-a mediator of inflammation or mucosal defence? Eur $\mathcal{F}$ Gastroenterol Hepatol 1997;9:102632 .

12 Kubes P. Inducible nitric oxide synthase: a little bit of good in all of us. Gut 2000;47:6-9.

13 Middleton SJ, Shorthouse M, Hunter JO. Increased nitric oxide synthesis in ulcerative colitis. Lancet 1993;341:465-6.

14 Boughton-Smith NK, Evans SM, Hawkey CJ, et al. Nitric oxide synthase activity in ulcerative colitis and Crohn's disease. Lancet 1993;342:338-40.

15 Lundberg JON, Hellström PM, Lundberg JM, et al. Greatly increased luminal nitric oxide in ulcerative colitis. Lance 1994;344:1673-4

16 Singer II, Kawka DW, Scott S, et al. Expression of inducible nitric oxide synthase and nitrotyrosine in colonic epithelium in inflammatory bowel disease. Gastroenterology 1996; 111:871-85.

17 Halliwell B. What nitrates tyrosine? Is nitrotyrosine specific as a biomarker of peroxynitrite formation in vivo? FEBS Lett 1997;411:157-60

18 Beckman JS, Koppenol WH. Nitric oxide, superoxide, and peroxynitrite: the good, the bad, and the ugly. Am F Physio peroxynitrite: the good,

19 Stack W, Filipowicz B, Hawkey C. Nitric oxide donating compounds stimulate human colonic ion transport in vitro. Gut 1996;39:93-9.

20 Binder V. A comparison between clinical state, macroscopic and microscopic appearances of rectal mucosa, and cytologic picture of mucosal exudate in ulcerative colitis Scand F Gastroenterol 1970;5:627-32.

21 Lowry OH, Rosebrough NJ, Farr AL, et al. Protein measurements with folin phenol reagent. $f$ Biol Chem 1951;193:265-75
22 Schmidt HH, Murad F. Purification and characterization of a human NO synthase. Biochem Biophys Res Commun 1991; 181:1372-7.

23 Rask-Madsen J. Simultaneous measurement of electrical polarisation and electrolyte transport by the entire normal and inflamed human colon during in vivo perfusion. Scand 7 Gastroenterol 1973;8:327-36.

24 Devroede GJ, Phillips SF. Studies of the perfusion technique for colonic absorption. Gastroenterology 1969;56:92-100.

25 Faraci WS, Nagel AA, Verdries KA, et al. 2-amino-4methylpyrididine as a potent inhibitor of inducible NO synthase activity in vitro and in vivo. Br F Pharmacol 1996; 119:1101-8.

26 Moshage H, Kok B, Huizenga JR, et al. Nitrite and nitrate determinations in plasma: a critical evaluation. Clin Chem 1995;41:892-6.

27 Kuo J, Fox E. Sigma Stat manual. Microcomputer tools for scientist. Revision SSD-1.0. Augsburg: Jandel Scientific, 1992.

28 Dijkstra G, Moshage H, Van-Dullemen HM, et al. Expression of nitric oxide synthases and formation of nitrotyrosine and reactive oxygen species in inflammatory bowel disease. F Pathol 1998;186:416-21.

29 Kimura H, Miura S, Shigematsu T, et al. Increased nitric oxide production and inducible nitric oxide synthase activity in colonic mucosa of patients with active ulcerative colitis and Crohn's disease. Dig Dis Sci 1997;42:1047-54.

30 Kimura H, Hokari R, Miura S, et al. Increased expression of an inducible isoform of nitric oxide synthase and the formation of peroxynitrite in colonic mucosa of patients with active ulcerative colitis. Gut 1998;42:180-7.

31 Gaginella TS, Mascolo N, Izzo AA, et al. Nitric oxide as a mediator of bisacodyl and phenolphthalein laxative action: induction of nitric oxide synthase. F Pharmacol Exp Ther 1994;270:1239-45.

32 Roberts PJ, Morgan K, Shorthouse M, et al. Inducible NOS (iNOS) is expressed in the normal human colon. Gastroenterology 1997;112:A1073.

33 Järnerot G, Tysk C, Bohr J, et al. Collagenous colitis and fecal stream diversion. Gastroenterology 1995;109:449-55.

34 Tepperman BL, Brown JF, Whittle BJ. Nitric oxide synthase induction and intestinal epithelial cell viability in rats. $A m \mathcal{F}$ Physiol 1993;265:G214-18.

35 Grisham MB, Specian RD, Zimmerman TE. Effects of nitric oxide synthase inhibition on the pathophysiology observed in a model of chronic granulomatous colitis. 7 Pharmacol Exp Ther 1994;271:1114-21.

36 Ribbons KA, Currie MG, Connor JR, et al. The effect of inhibitors of inducible nitric oxide synthase on chronic colitis in the rhesus monkey. I Pharmacol Exp Ther 1997;280:1008-15.

37 Wallace JL, Vergnolle N, Muscara MN, et al. Enhanced anti-inflammatory effects of a nitric oxide-releasing derivative of mesalamine in rats. Gastroenterology 1999;117:55766.

38 McCafferty DM, Mudgett JS, Swain MG, et al. Inducible nitric oxide synthase plays a critical role in resolving intestinal inflammation. Gastroenterology 1997;112:1022-7.

39 Zingarelli B, Szabó C, Salzman A. Reduced oxidative and nitrosative damage in murine experimental colitis in the absence of inducible nitric oxide synthase. Gut 1999;45: 199-209.

40 Eiserich JP, Hristova M, Cross CE, et al. Formation of nitric oxide-derived inflammatory oxidants by myeloperoxidase in neutrophils. Nature 1998;391:393-7.

41 Lazenby AJ, Yardley JH, Giardiello FM, et al. Lymphocytic ('microscopic') colitis: a comparative histopathologic study with particular reference to collagenous colitis. Hum Pathol 1989;20:18-28.

42 Perner A, Andresen L, Pedersen G, et al. Superoxide production in DLD-1 and HT-29 epithelial cell lines and in primary epithelial cells from normal human colon. Gastroenterology 2000;118:A98. 